\title{
Zagreb Earthquakes on 22nd March 2020 and Geomagnetic Information
}

\author{
Mario BRKIĆ ${ }^{*}$ Marijan GRGIĆ, Nikol RADOVIĆ
}

\begin{abstract}
Earthquakes in the Zagreb area on $22^{\text {nd }}$ March 2020 were an occasion to estimate earthquake-related noise in minute magnetograms and its significance to the geomagnetic information renewal i.e.,survey of geomagnetic networks, reduction, and modelling of the geomagnetic information (that is, declination and its annual variation). Firstly, the distinction of geomagneticaly quiet and disturbed days was vividly portrayed by comparison of Q1 (quiet) and D1* (disturbed) days of March 2020 in the geomagnetic observatory Lonjsko polje magnetograms. The day of $22^{\text {nd }}$ March was rather quiet geomagnetic day, therefore the comparison of available magnetograms of the observatories Lonjsko polje and Nagycenk was performed. Identification of earthquakes on magnetograms was limited by the uncertainties of observatory and epicentre coordinates, magnitudes of the earthquake waves' velocities, times of their occurrence at observatories, rounding of earthquakes times to whole minutes, and filtering observatories' records into minute (and preliminary) magnetograms. Comparisons of observatories minute magnetograms during the observed day did not unequivocally indicate earthquakes; seemingly the earthquakes noise was less than the effects of the quiet days' geomagnetic disturbances. The differences of variations, obtained by removing the diurnal variation from centred magnetograms, in Lonjsko polje and Nagycenk, at the earthquakes' times were found negligible, less than 10 " for the declination, $5 \mathrm{If}$ for the inclination, and $0.6 \mathrm{nT}$ for the total intensity. Thus, the contribution of the noise of earthquakes of comparable features was estimated negligible in the context of the geomagnetic information renewal.
\end{abstract}

Keywords: geomagnetic information renewal; magnetic noise of earthquakes

\section{INTRODUCTION}

Earth's magnetic field (see e.g., [1-4]) declination and its annual variation, as map's marginal geomagnetic information (GI), is essential in orientation and navigation by compass. The $2{ }^{\text {nd }} \mathrm{Cycle}$ on the Geomagnetic Information Renewal in Croatia started in 2017 with the main goal to provide updated geomagnetic information over the territory of Croatia based on the geomagnetic measurements on the Croatian Geomagnetic Repeat Stations Network [5]. The undesirable conditions and geomagnetic observations errors, the proposed reduction accuracies, and contributions of processing steps to the error budget have been reported in [6-9]. Investigations on Earth's magnetic field connections to earthquakes may be found in e.g. [10-15]. Different studies, mostly focusing on the major earthquake zones, reported on the preceding magnetic anomalies that accompanied large earthquakes (see e.g., [14]), investigated the geomagnetic diurnal variations associated with the earthquakes (see e.g., [16-
17]), or tried to explain the distance relationships between the anomalies and the earthquakes (see e.g., [15]). Recent studies [18-19] indicate earthquake-related changes in the amount of energy in the local Earth's magnetic field i.e., additional magnetic noise. Opportunity to study earthquake-related effects on geomagnetic survey [16] came recently in the form of the Zagreb area earthquakes [20]. Thus, we have investigated the contribution of the selected earthquakes (see Tab. 1) at minute magnetograms of the observatories LONjsko polje (LON) in Croatia and NagCyenK (NCK) in Hungary to get an insight on the noise in declination $(D)$, inclination $(I)$, and total intensity $(F)$. The study aimed at answering whether the noise generated by the similarly strong earthquakes, in relative proximity to these observatories (which simulate the locations of geomagnetic network), is significant in the setting of geomagnetic network survey, reductions, and monitoring of the Earth's magnetic field in Croatia.

Table 1 EMSC (European Mediterranean Seismological Centre) info. on the earthquakes of magnitude $\geq 3$ in the Zagreb area on 22 ${ }^{\text {nd }}$ March 2020 [21]

\begin{tabular}{|c|c|c|c|c|}
\hline UTC & Latitude/dec.deg & Longitude /dec.deg & Depth / km & Magnitude / Richter \\
\hline $05: 24: 02$ & 45.87 & 16.02 & 10 & 5.4 \\
\hline $06: 01: 20$ & 45.87 & 16.00 & 10 & 5.0 \\
\hline $06: 41: 05$ & 45.89 & 16.02 & 2 & 3.7 \\
\hline $08: 04: 01$ & 45.87 & 15.98 & 7 & 3.1 \\
\hline $08: 10: 26$ & 45.87 & 15.95 & 2 & 3.0 \\
\hline $09: 11: 57$ & 45.87 & 16.05 & 4 & 3.3 \\
\hline
\end{tabular}

Table 2 Geomagnetic indices on the quietest and disturbed days of March 2020, and the day the earthquakes occurred (22 ${ }^{\text {nd }}$ March 2020)

\begin{tabular}{|c|c|c|c|c|c|c|c|c|c|c|}
\hline Date & $\mathrm{Q} / \mathrm{D}$ & $K p$ & $K p$ & $K p$ & $K p$ & $K p$ & $K p$ & $K p$ & $K p$ & $A p$ \\
\hline $11-03-2020$ & $\mathrm{Q} 2$ & -2 & $0+$ & $0+$ & -1 & -1 & $0+$ & $0 \mathrm{o}$ & $0+$ & 2 \\
\hline $14-03-2020$ & $\mathrm{Q} 1$ & $0 \mathrm{o}$ & $0 \mathrm{o}$ & $0+$ & -1 & -1 & $0+$ & $1 \mathrm{o}$ & -1 & 2 \\
\hline $22-03-2020$ & & $2+$ & $2 \mathrm{o}$ & $1 \mathrm{o}$ & $1 \mathrm{o}$ & $1+$ & -2 & $2+$ & -2 & 6 \\
\hline $31-03-2020$ & $\mathrm{D} 1 *$ & $3+$ & $4 \mathrm{o}$ & -4 & $2 \mathrm{o}$ & $3 \mathrm{o}$ & -3 & $2+$ & $1+$ & 14 \\
\hline
\end{tabular}

The feasibility of the research idea was based on the fact that March 2020 was a relatively quiet geomagnetic month, see table kp2003.tab from [22], from which the 3hourly $K p$ (standardized "planetary" $K$-index of the geomagnetic activity) and $A p$ indices (daily average level for geomagnetic activity) are shown in Tab. 2 for two quietest days of the month Q1 and Q2, a 'not really' disturbed day D1* (disturbed day with $A p<20$, marked with asterisk), and the day the Zagreb earthquakes occurred. The $21^{\text {st }}$ March 2020 was geomagnetically 
disturbed day, $\mathrm{D}^{*}$. Out of the list of the Zagreb earthquakes with the magnitude $\geq 3.0$, the one that occurred on the $23^{\text {rd }}$ March was not analysed since that day was marked D2*, (not really) disturbed. The $24^{\text {th }}$ March was also not analysed due to its magnitude of 3.2 , which is close to the magnitudes of the fourth and sixth earthquake on $22^{\text {nd }}$ March. Thus, the only earthquakes considered were those of the highest magnitudes that occurred on the $22^{\text {nd }}$ March, which can be considered a quiet geomagnetic day, i.e., appropriate for geomagnetic survey (see Tab. 2).

\section{THE QUIETEST VS THE MOST DISTURBED DAY OF MARCH 2020 AT LON}

Available non-definite $(v)$ filtered minute data of LON [23] magnetic elements (E) $X, Y, Z$ in IAGA-2002 format
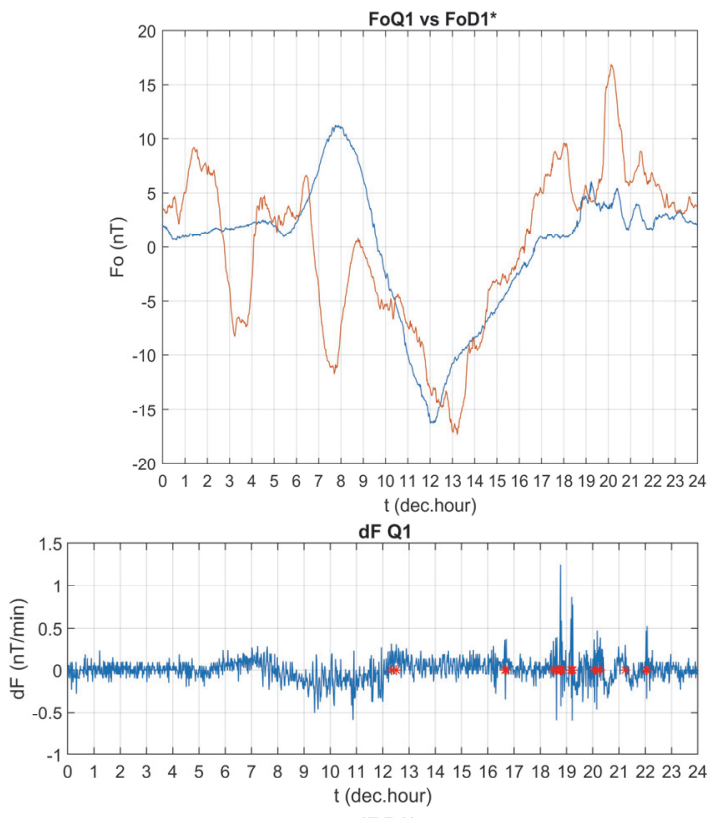

dF D1
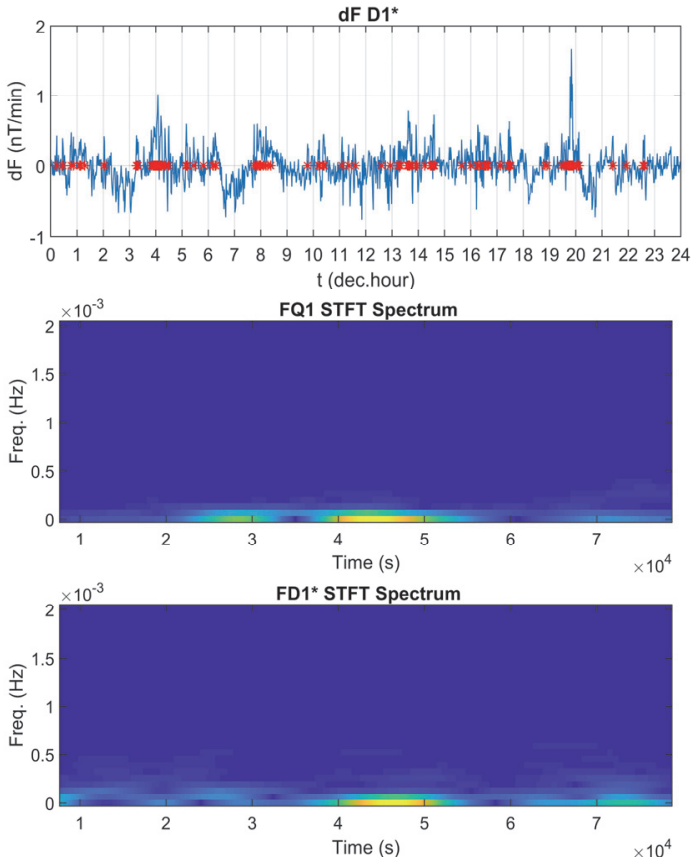

were firstly verified and converted into $D, I$, and $F$ elements. In our analysis it was desirable to create a statistical and visual reference about quiet days because the intention was to notice the effect of earthquakes in such days. A comparison of the Q1 and D1* March 2020 magnetograms at LON gives a glimpse on the quiet and disturbed days and their differences (Tab. 3 and Fig. 1). The similar geomagnetic conditions were assumed for the NCK observatory, which is taken into consideration in the next chapter. Although some parameters given in Tab. 3 on D1* day might look like those on Q1 day, Fig. 1 leaves no doubt on the character of the $\mathrm{D} 1 *$ which was defined as a not really disturbed day. Indeed, note that $K p$ indices 3 and 4 of the $31^{\text {st }}$ March 2020 exceed the acceptable disturbances limit $\left(K_{T H Y} \leq 2\right)$ for the geomagnetic surveys, which confirms that there were no significant geomagnetic disturbances in March.
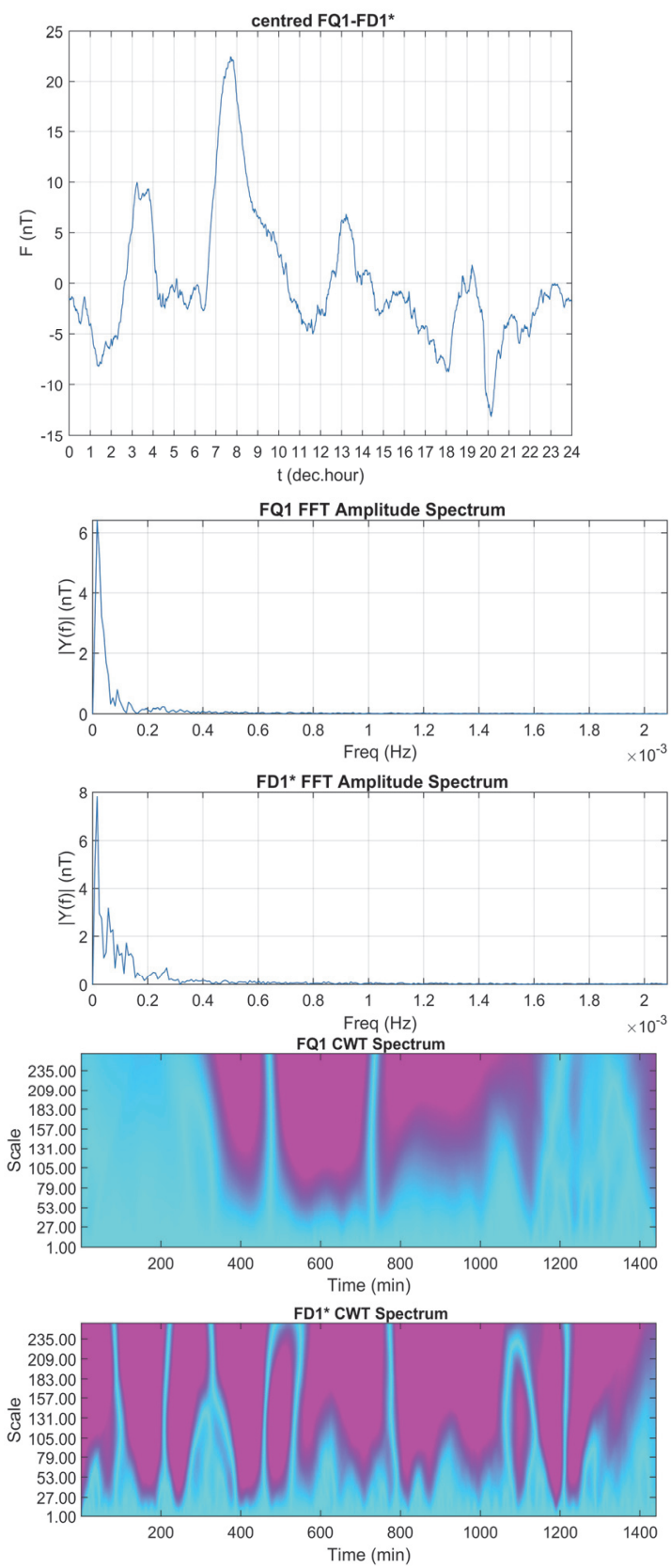

Figure $1 \mathrm{~A}$ visual reference of quiet and disturbed days of March 2020. Top row: centred total intensity Foon Q1 (blue) and D1* (red) day (left) illustrate distortions in form and magnitude, as well as rapid transient variation pronounced more during the diurnal variation (right). Middle row: disturbances are present in magnitude range of the first derivative of $F$ and numerous jumps marked with red stars (left), as well as in the magnitude and peaks of FFT amplitude spectra (right). Bottom row: again, the STFT (left) and CWT (right) spectra distinguish the quiet and disturbed days. Of course, these differences are more pronounced during magnetic storms 
Table 3 A statistical overview magnetic elements $D, I$ and $F$ on $Q 1$ and $D 1^{*}$ days of March 2020 at LON

\begin{tabular}{|c|c|c|c|}
\hline & $D$ & $I$ & $F$ \\
\hline Range of centred element E0 on Q1 day & 0.08 dec.deg & 0.02 dec.deg & $27.5 \mathrm{nT}$ \\
\hline Range of centred element E0 on D1* day & 0.16 dec.deg & 0.05 dec.deg & $34.1 \mathrm{nT}$ \\
\hline Minute variation of E0 on Q1 day & $5.3 \mathrm{E}-05$ dec.deg & $1.6 \mathrm{E}-05$ dec.deg & $1.9 \mathrm{E}-02 \mathrm{nT}$ \\
\hline Minute variation of E0 on D1* day & $1.1 \mathrm{E}-04$ dec.deg & $3.2 \mathrm{E}-05$ dec.deg & $2.4 \mathrm{E}-02 \mathrm{nT}$ \\
\hline No of magnetic element E jumps on Q1 & & & 20 \\
\hline No of magnetic element $\mathrm{E}$ jumps on $\mathrm{D} 1 *$ & & & 132 \\
\hline Range of centred difference of E on Q1 and E on D1* & 0.12 dec.deg & 0.06 dec.deg & $35.6 \mathrm{nT}$ \\
\hline Element Correlation Coefficient CC of Q1/D1* & 0.6901 & 0.2425 & 0.5540 \\
\hline St. dev. of the element's 4th derivative on Q1 & 0.002 dec.deg $/ \mathrm{min}^{4}$ & $0.001 \mathrm{dec} \cdot \mathrm{deg} / \mathrm{min}^{4}$ & $0.6 \mathrm{nT} / \mathrm{min}^{4}$ \\
\hline Range of the element's 4th derivative on Q1 & $0.032 \mathrm{dec} . \mathrm{deg} / \mathrm{min}^{4}$ & $0.016 \mathrm{dec} . \mathrm{deg} / \mathrm{min}^{4}$ & $10.6 \mathrm{nT} / \mathrm{min}^{4}$ \\
\hline St. dev. of the element's 4 th derivative on $\mathrm{D} 1 *$ & $0.002 \mathrm{dec} . \mathrm{deg} / \mathrm{min}^{4}$ & $0.001 \mathrm{dec} . \mathrm{deg} / \mathrm{min}^{4}$ & $0.6 \mathrm{nT} / \mathrm{min}^{4}$ \\
\hline Range of the element's 4 th derivative on D1* & $0.025 \mathrm{dec} . \mathrm{deg} / \mathrm{min}^{4}$ & 0.015 dec.deg $/ \mathrm{min}^{4}$ & $6.5 \mathrm{nT} / \mathrm{min}^{4}$ \\
\hline
\end{tabular}

Centred elements $(\mathrm{E} 0=\mathrm{E}-\overline{\mathrm{E}})$ show a substantially smaller range on a quiet day than on a disturbed day, as well as a smaller minute variation, and the number of jumps (first derivatives greater than $0.3 \mathrm{nT}$ ); the distinction between $\mathrm{Q} 1$ and $\mathrm{D} 1 *$ is indicated by the range of the centred difference of the elements for those days, as well as the correlation coefficient, while the 4th derivative is an indicator of noise.

The statistics are supplemented by Fig. 1: distorted D1* graphs of centred D, I and F elements, more pronounced first (as well as fourth) derivatives, and additional periodicities (frequencies) in Fast Fourier Transform (FFT) analysis. In the Short Time Fourier Transform (STFT) analysis the disturbance energy is evident at higher frequencies also throughout whole day. The Continuous Wavelet Transform (CWT) unveils clear additional periodicities as disturbances located at higher frequencies in rapidly changing details throughout the day in respect to quiet Q1 day. The considered parameters are part of the QC (Quality Control) analysis that serve to assess the acceptability of geomagnetic field survey in order to avoid repeating it [9]. In contrast to the not so large but still significant difference between $\mathrm{Q} 1$ and D1* presented above, a considerably smaller difference was obtained for the between the quiet Q1 and Q2 day; however, the Q1 day can only to some extent represent the other $Q$ days and in the identification of the earthquake one should turn to the comparison of the LON with another reference, i.e., another observatory. The selected reference observatory should be far away so that the earthquake waves attenuate it more and arrive with a greater delay than at the LON, but also close enough so that the Earth's magnetic field is comparable.

\section{LON AND NCK MAGNETOGRAMS ON MARCH 22, 2020}

$22^{\text {nd }}$ March 2020 was not a Q day, but the earthquakes took place in quiet conditions $(A p=6)$, see Fig. 2. The comparison of the LON and the THY Observatory (Tihany, Hungary, approximately $192 \mathrm{~km}$ northeast of LON) was not possible because the qmin INTERMAGNET data [24] of Y component were unusable for that day from 5:25 UTC onwards. From the available (not final data at the time of the study, July of 2020) INTERMAGNET data, it was possible to compare the LON and NCK, which is located at a close distance of $244 \mathrm{~km}$, while DUR (Duronia, Italy) and FUR (Fürstenfeldbruck, Germany), with the distances of 454 and $513 \mathrm{~km}$, respectively, are possibly too far away, so the magnetic field variations may be too dissimilar as previous studies have suggested (see e.g. [25]). This again invokes a question of a need for the second observatory in the Republic of Croatia, positioned preferably in central Dalmatia.

Distances from LON to the earthquake hypocentres of the earthquakes that occurred on $22^{\text {nd }}$ March 2020 (see Tab. 1) were approximately $72,73,73,74,75$, and $70 \mathrm{~km}$, respectively. Although only S waves velocity of $3.5 \mathrm{~km} / \mathrm{s}$ for the Zagreb earthquakes is known [20, 27], nonetheless the shear waves have greater amplitude than primary waves and are responsible for vertical and horizontal motion of the ground, thus $\mathrm{S}$ waves effects are of interest.

Assuming non-realistic, linear propagation of S waves from the earthquakes focus, without any discontinuity on the path, delays in arrival times of the $\mathrm{S}$ waves at LON observatory found were around 20,21,21,21, 21, and 20 $\mathrm{s}$, respectively. Since the publicly available coordinates of the observatories, as well as the epicentres, are known only approximately (resulting in distance uncertainties of about $1 \mathrm{~km}$ and $10 \mathrm{~km}$ respectively), and without declared geodetic reference system, along with the wave velocities not modelled particularly for the area of consideration, the times of arrivals of earthquake waves at the observatories were approximate. Additional uncertainty in the identification of earthquakes on the magnetogram is introduced by rounding hh:mm:ss of the earthquake time to hh:mm, while minute magnetograms are created by filtering subintervals $\left(\mathrm{mm}^{-1}\right): 15 \mathrm{~mm}: 45$.

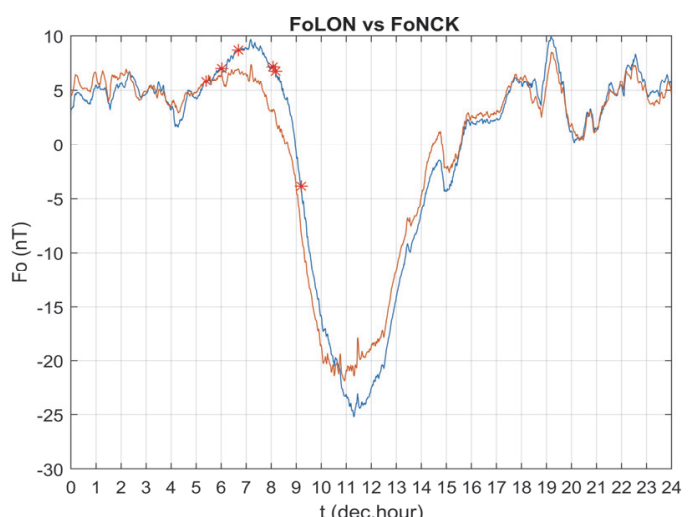

Figure 2 Centred $F$ at LON (blue magnetogram; red asterisks roughly indicate earthquakes arrivals) vs centred Fat NCK (red magnetogram) on $22^{\text {nd }}$ March 2020

Filtered minute data intervals of the magnetograms are suitable for data reductions of geomagnetic surveys (see 
e.g., $[2,7])$. However, it would be desirable to analyse both minute and 1-second magnetograms in the future. The estimated times of arrivals of $\mathrm{S}$ earthquake waves on the LON (represented by the red asterisks in the following figures) were rounded to minutes: 5:24, 6:01, 6:41, 8:04, 8:10, and 9:12 UTC. Delays in arrivals of $S$ earthquake waves at the NCK are approximately $56,56,56,56,57,56$ $\mathrm{s}$, respectively, so that the occurrences of $\mathrm{S}$ waves fall at 5:24, 6:02, 6:42, 8:04, 8:11, and 9:12 UTC, respectively. Accordingly, the waves, presumably weakened, get to NCK during the same minute or a minute later than they get to LON. Occurrence times fall in intervals with acceptable $K p$ indices (Tab. 2). LON $\mathrm{K}$ indices at earthquake arrival times were 2,1 , and 2; therefore, the conditions are quiet and favourable for the comparison of LON and NCK magnetograms (Fig. 2). The general comparability of the Earth's magnetic fields at LON and NCK, as a precondition for earthquake search, was also evident in the correlation coefficients (Tab. 5).

If there were a significant contribution of the earthquake, it would have been recognized on the LON
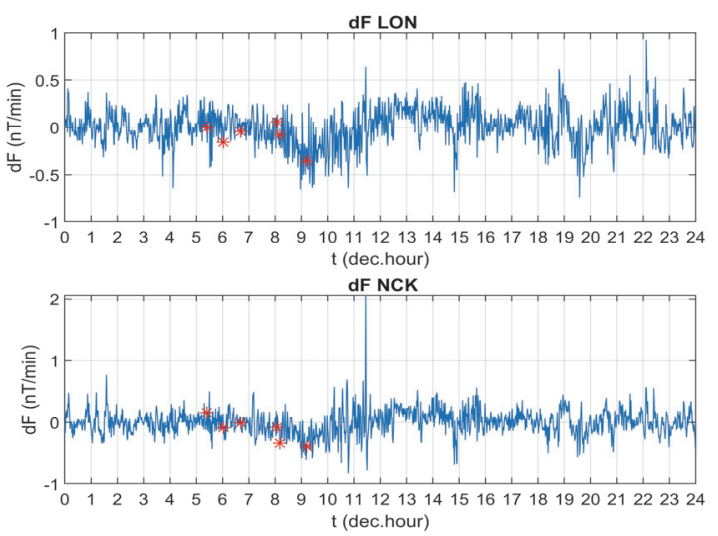

Figure 3 The first (left) and the fourth (right) derivative of total intensity at LON and NCK on 22 ${ }^{\text {nd }}$ March 2020

The first temporal derivative of the $D, I$, and $F$ elements could indicate jumps or peaks as a consequence of an event; in the minutes of the earthquakes the maximum absolute magnitudes of the jumps on the LON were negligible: 0.1 'for $D, 0.1$ ' for $I$ and $0.4 \mathrm{nT}$ for $F$, and Fig. 3 is comparable to Fig. 1 for Q1 day.

The fourth derivatives were adapted as a method of detecting of man-made noises [9]; the method tested here shows the usual levels of a quiet day (compare Tab. 5 and Tab. 3), and earthquake contributions, if any, are not obvious (Fig. 3).

In the FFT spectrum of the $F$ series at LON and NCK (Fig. 4), there were no noticeable earthquakes a series of short-term events which trigger short-period oscillations that quickly deteriorate in time. Neither STFT nor CWT F sequences showed the presence of earthquakes. Only periodicities of quiet diurnal variation are dominant. Compared to the previous analysis of the quietest and the most disturbed day, it seems that earthquake noise is significantly less than $Q$ day disturbances and much smaller than the disturbances of the $\mathrm{D}$ days.

Statistical parameters of the comparison at LON and NCK on the day of the Zagreb earthquake were given in Tab. 5. If compared to Tab. 3, it is apparent that they are more similar to the parameters of a quiet than a disturbed day. magnetogram as an asterisk on the peak (or as a peak close to the asterisk), which does not exist at the same time (at least not to the same extent) on the NCK magnetogram (Fig. 2). A closer inspection does not reveal that for the first two stronger earthquakes nor the other four. The differences of the centred elements follow from the different variations of the Earth's magnetic field at LON and NCK, and at the time of the earthquakes on LON these differences for the considered earthquakes are generally not large but are not negligible (Tab. 4). We will look into their content later, but now let us investigate if other QC methods for evaluation of geomagnetic surveys may indicate earthquakes.

Table 4 Differences of centred elements on LON and NCK at times of six earthquakes on $22^{\text {nd }}$ March 2020

\begin{tabular}{|r|r|r|r|r|r|r|}
\hline $\mathrm{Do}^{\mathrm{LON}}-\mathrm{Do}^{\mathrm{NCK}} /{ }^{\prime}$ & -0.4 & -0.2 & -0.2 & -0.2 & -0.2 & 0.1 \\
\hline $\mathrm{Io}^{\mathrm{LON}}-\mathrm{Io}^{\mathrm{NCK}} / '$ & 0.1 & 0.1 & 0.0 & -0.1 & -0.2 & -0.5 \\
\hline $\mathrm{Fo}^{\mathrm{LON}}-\mathrm{Fo}^{\mathrm{NCK}} / \mathrm{ITT}^{\mathrm{L}}$ & 0.2 & 0.5 & 1.7 & 4.0 & 4.0 & 4.0 \\
\hline
\end{tabular}
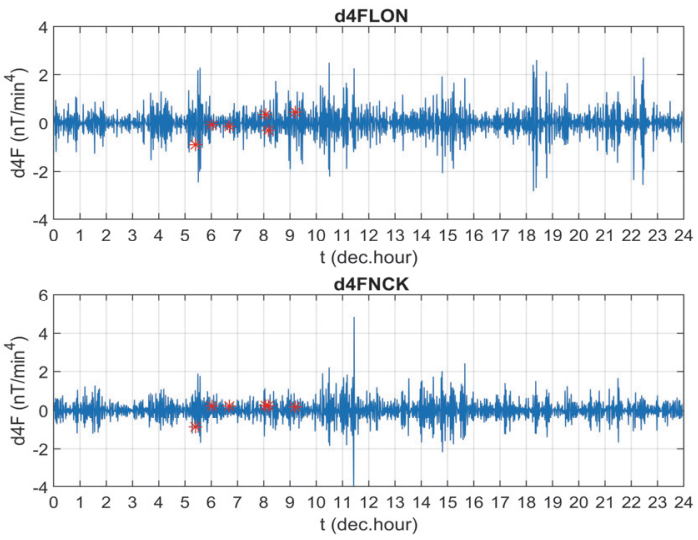

If we assume that the values in Tab. 4 contain the earthquake contribution, the next step of analysis was to remove the Diurnal Variations $(D V)$ from the centred magnetograms and look for the differences of variations at the LON and NCK. The $D, I$, and $F$ elements at LON and NCK on the observed day were centred by subtraction of the mean, while the Fast Fourier Transform analysis determined smooth $D V$ of each element and observatory with $24,12,8$ and 6 hourly periods, as the expansion of coefficients (see e.g. [26] and the references therein):

$D V=\sum_{1}^{4}\left[a_{n} \cos (2 \pi n t / 1440)+b_{n} \sin (2 \pi n t / 1440)\right]$

Declination differences between centred and $D V$ values at the moments of the earthquakes at LON were 0.2 , $-0.1,-0.1,-0.3,-0.3$, and 0.3 arcminutes at LON, and 0.3 , $-0.2,-0.2,-0.2,-0.2$, and 0.3 arcminutes in the same moments at NCK. Subtracting these variations for LON and NCK we obtain the values $-7,10,3,-3,-4$, and -2 arcseconds. Accordingly, the contribution of the considered earthquakes, (if) exists in the stated values, is negligible in the context of geomagnetic information renewal. 
Table 5 The comparison of selected statistical parameters at LON and NCK on 22 ${ }^{\text {nd }}$ March 2020

\begin{tabular}{|c|c|c|c|}
\hline & $D$ & $I$ & $F$ \\
\hline Range of cantered element Eo at LON & 0.13 dec.deg & 0.03 dec.deg & $35.1 \mathrm{nT}$ \\
\hline Range of cantered element Eo at NCK & 0.14 dec.deg & 0.03 dec.deg & $30.4 \mathrm{nT}$ \\
\hline Minute variation of Eo at LON & 8.9E-05 dec.deg & $2.3 \mathrm{E}-05$ dec.deg & $2.4 \mathrm{E}-02 \mathrm{nT}$ \\
\hline Minute variation of Eo at NCK & 9.9E-05 dec.deg & $2.0 \mathrm{E}-05$ dec.deg & $2.1 \mathrm{E}-02 \mathrm{nT}$ \\
\hline No of magnetic element $\mathrm{E}$ jumps at LON & & & 68 \\
\hline No of magnetic element E jumps at NCK & & & 86 \\
\hline Maximal absolute difference of Eo at LON and NCK & 0.4 dec.deg & 0.5 dec.deg & $4.0 \mathrm{nT}$ \\
\hline Element Correlation Coefficient CC of LON/NCK & 0.9945 & 0.8703 & 0.9799 \\
\hline St. dev. of the element's 4th derivative at LON & $0.003 \mathrm{dec} . \mathrm{deg} / \mathrm{min}^{4}$ & $0.001 \mathrm{dec} . \mathrm{deg} / \mathrm{min}^{4}$ & $0.6 \mathrm{nT} / \mathrm{min}^{4}$ \\
\hline Range of the element's 4th derivative at LON & $0.038 \mathrm{dec} . \mathrm{deg} / \mathrm{min}^{4}$ & $0.012 \mathrm{dec} . \mathrm{deg} / \mathrm{min}^{4}$ & $5.5 \mathrm{nT} / \mathrm{min}^{4}$ \\
\hline St. dev. of the element's 4th derivative at NCK & $0.004 \mathrm{dec} . \mathrm{deg} / \mathrm{min}^{4}$ & $0.001 \mathrm{dec} . \mathrm{deg} / \mathrm{min}^{4}$ & $0.6 \mathrm{nT} / \mathrm{min}^{4}$ \\
\hline Range of the element's 4th derivative at NCK & $0.055 \mathrm{dec} . \mathrm{deg} / \mathrm{min}^{4}$ & $0.017 \mathrm{dec} . \mathrm{deg} / \mathrm{min}^{4}$ & $8.8 \mathrm{nT} / \mathrm{min}^{4}$ \\
\hline
\end{tabular}
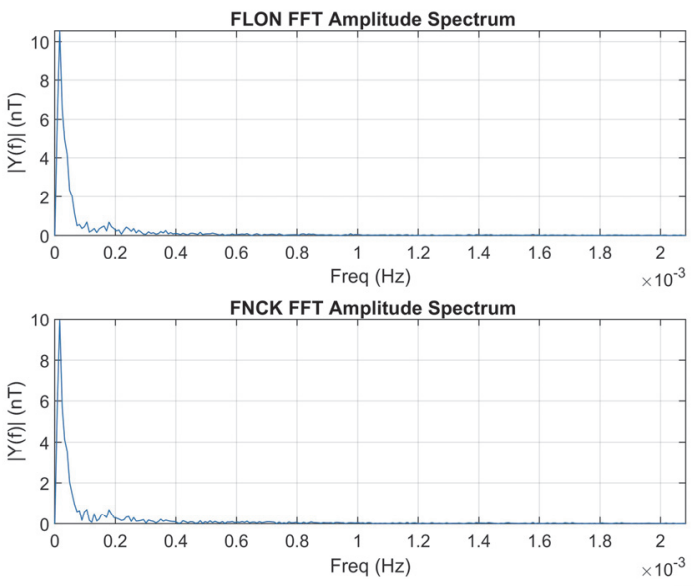
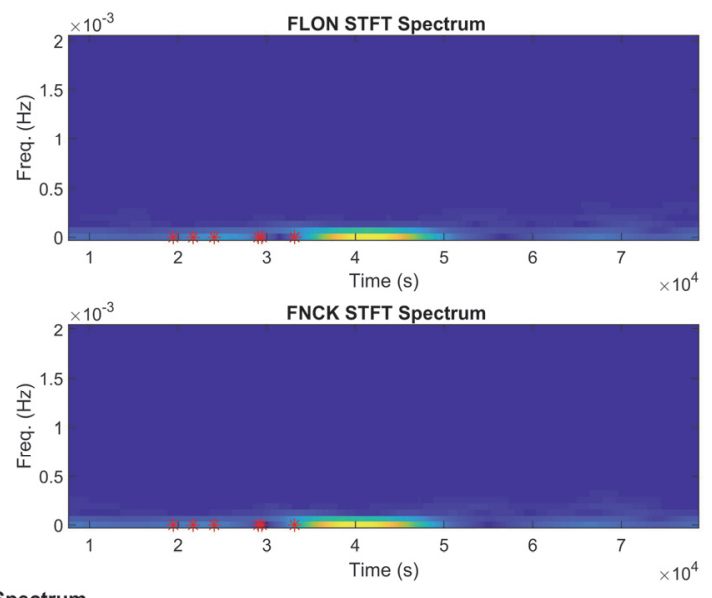
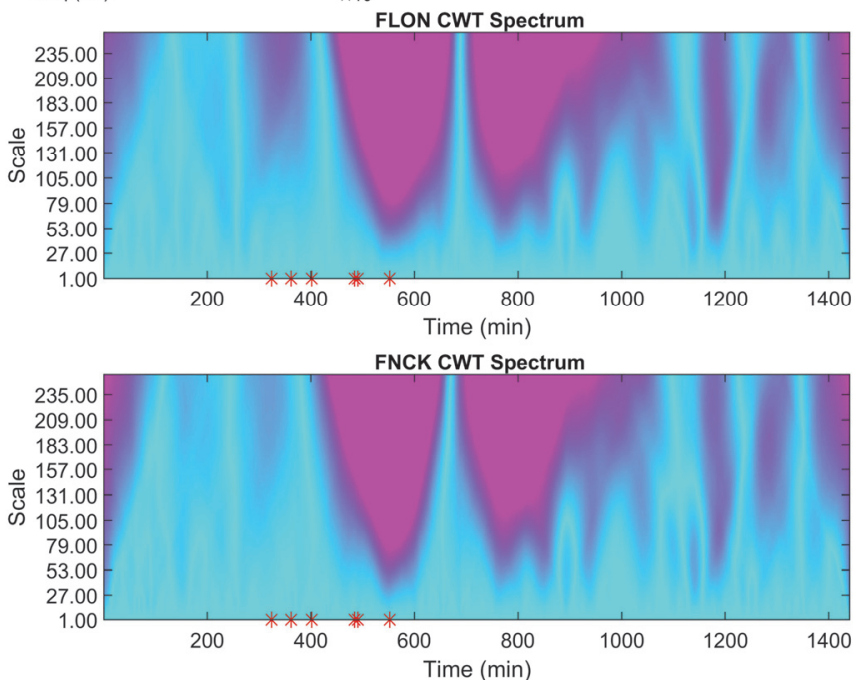

Figure $4 \mathrm{FFT}$, STFT and CWT total intensity spectra at LON and NCK on 22nd March 2020

For the inclination, the centred minus $D V$ values at the moments of earthquakes at LON were $0.1,0.1,-0.1,0.0$, -0.1 , and 0.1 arcminutes, and at NCK $0.1,0.1,-0.1,-0.1$, -0.1 , and 0.1 arcminutes. The difference of variations at LON and NCK gave $0,-2,-1,4,5$, and -3 arcseconds. Total intensity differences between centred and $D V$ at the moments of the earthquakes at LON were $0,-1.1,-1.1$, $1.0,1.5$, and $1.2 \mathrm{nT}$, and at NCK $-0.1,-0.8,-0.8,1.1,1.6$, and $0.6 \mathrm{nT}$. The differences of these variations at LON and NCK were $0.2,-0.4,-0.4,0.0,0.0$, and 0.6 nT (Fig. 5).

Finally, we can state that there is no clear correlation between the magnitude of the earthquakes and the values of the differences, so we assume that only a part of the amount of the difference is the contribution of the earthquakes. The comparability of the values of the differences around the time of the earthquakes' occurrences is evident, so the question of the temporal uncertainty of the earthquake arrivals at LON and NCK is not crucial see LON(Fo-FDV) - NCK(Fo-FDV) graph of Fig. 5. However, repeating of the QC analyses of variations depicted in such a difference is left for the future. 

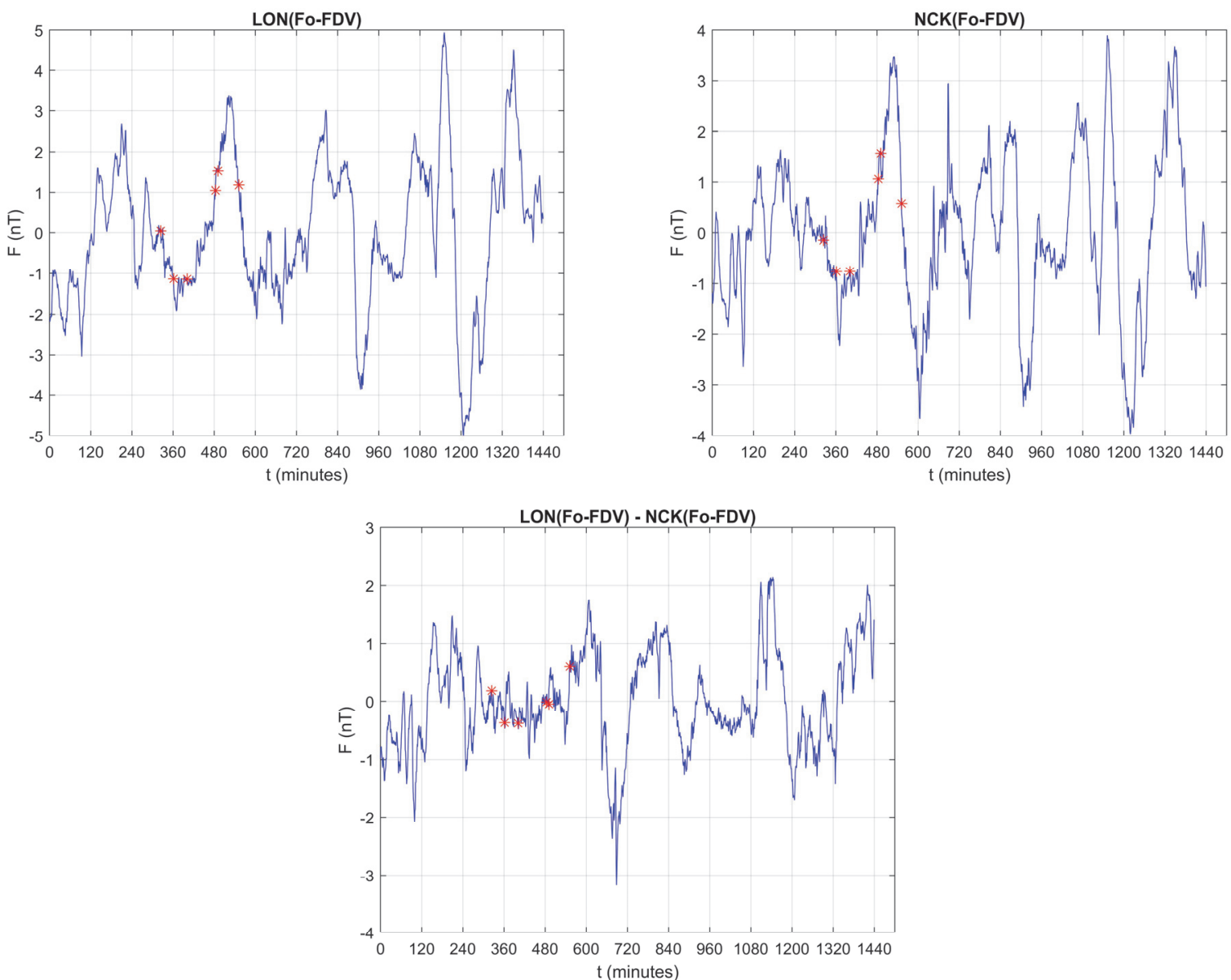

Figure 5 Transient time variations after removal of diurnal variation from centred total intensity at LON, and NCK, and their differences (bottom) on $22^{\text {nd }}$ March 2020

\section{CONCLUSION}

Imagine $D-I-F$ measurements at the geomagnetic repeat stations network site, and/or at the geomagnetic observatory, far enough from the hypocentre, such that the surveyor is not aware of the ongoing earthquake (geomagnetic measurements of declination and inclination would be impossible during noticeable trembling). Further assume that earthquake magnetic noise is present at the exact moments of measurements, i.e., during a few minutes that it takes to make a declination set of (the null-method of) measurements, as well as a few minutes for an inclination set, and a few or more minutes for the total intensity determination. This may imply earthquake magnetic noise contribution in minute $D, I$, and $F$ measurements, obtained at repeat station(s) and/or observatory(ies), which may further propagate into the reduced elements (annual means), models, and maps.

Thus, the study aimed to determine whether not far and shallow earthquakes of magnitudes comparable to the earthquakes occurred in the Zagreb area on $22^{\text {nd }}$ March 2020 are visible in minute INTERMAGNET magnetograms, which are regularly used in QC analysis immediately after the geomagnetic survey, as well reductions afterwards. Negligible contributions are indicated pointing to the amounts less than 10 " for $D, 5^{\prime \prime}$ for $I$, and $0.6 \mathrm{nT}$ for $F$.

However, due to the uncertainty in the identification of earthquakes on the magnetogram, it is considered necessary to further analyse 1 - second magnetograms. Besides, it is necessary to improve the information about the exact and sufficiently precise coordinates of the observatory and earthquake foci, defined in the same geodetic reference system, and determine the velocities of earthquake waves on their ways, as well as times of arrivals to the observatories. To place the seismographs at the geomagnetic observatories would be advantageous. Therefore, as it was argued within previous studies, it is desirable to have, in addition to LON, another geomagnetic observatory in the Republic of Croatia.

\section{REFERENCES}

[1] Kono, M. (2015). Geomagnetism: An Introduction and Overview. Treatise on Geophysics. https://doi.org/10.1016/B978-0-444-53802-4.00095-6.

[2] Newitt, L. R., Barton, C. E., \& Bitterly, J. (1996). Guide for magnetic repeat station surveys, 325. Boulder, CO: International Association of Geomagnetism and Aeronomy.

[3] Mandea, M. \& Korte, M. (2010). Geomagnetic observations and models, 5. Springer Science \& Business Media. https://doi.org/10.1007/978-90-481-9858-0

[4] Campbell, W. H. (2003). Introduction to geomagnetic fields. Cambridge University Press. https://doi.org/10.1017/CBO9781139165136

[5] Grgić, M., Brkić, M., Varga, M., \& Budić, J. (2019). Activities on the 2nd Cycle of Geomagnetic Information Renewal in Croatia, EPOS TCS Geomagnetic Observations meeting with Users and Providers, Prague, Czech Republic.

[6] Brkić, M. (2019). Monitoring Geomagnetic Information in the Territory of Croatia. Geofizika, 36(2019), 1-15. https://doi.org/10.15233/gfz.2019.36.3

[7] Brkić, M., Vujić, E., Šugar, D., Jungwirth, E., Markovinović, D., Rezo, M., Pavasović, M., Bjelotomić, O., Šljivarić, M., 
Varga, M., \& Poslončec-Petrić, V. (2013). Osnovna geomagnetska mreža Republike Hrvatske 2004.-2012., s kartama geomagnetskog polja za epohu 2009.5, Brkić, M. (ur.). Državna geodetska uprava, Zagreb.

[8] Brkić, M., Vujić, E., Radović, N., Matika, D., \& Bašić, T. (2017). Geomagnetic Information Risk Revisited: a case study of Croatia. CODATA-Germany Lecture Notes in Information Sciences, 8, Risk Information Management, Risk Models and Applications, Selected Papers, Kremers, H., Susini, A. (ed.). 31-38.

[9] Brkić, M., Pavasović, M., Varga, M., \& Grgić, M. (2018). 2nd Geomagnetic Information Renewal Cycle in the Republic of Croatia-First Results. Cartography and Geoinformation, 17(2018), 30, 4-15. https://doi.org/10.32909/kg.17.30.1

[10] Moldovan, I. A., Placinta, A. O., Constantin, A. P., Moldovan, A. S., \& Ionescu, C. (2012). Correlation of geomagnetic anomalies recorded at MunteleRosu Seismic Observatory (Romania) with earthquake occurrence and solar magnetic storms. Annals of Geophysics, 55(1). https://doi.org/10.4401/ag-5367

[11] Ding, J. H., Liu, J., Yu, S. R., \& Xiao, W. J. (2004). Geomagnetic diurnal-variation anomalies and their relation to strong earthquakes. Acta SeismologicaSinica, 17(1), 8593. https://doi.org/10.1007/s11589-004-0070-9

[12] Love, J. J. \& Thomas, J. N. (2013). Insignificant solarterrestrial triggering of earthquakes. Geophysical Research Letters, 40(6), 1165-1170. https://doi.org/10.1002/grl.50211

[13] Kakinami, Y., Chen, C. H., Liu, J. Y., Oyama, K. I., Yang, W. H., \& Abe, S. (2009, August). Empirical models of Total Electron Content based on functional fitting over Taiwan during geomagnetic quiet condition. Annales Geophysicae, 27(8), 3321-3333. https://doi.org/10.5194/angeo-27-3321-2009

[14] Skordas, E. S. \& Sarlis, N. V. (2014). On the anomalous changes of seismicity and geomagnetic field prior to the 2011 Mw 9.0 Tohoku earthquake. Journal of Asian Earth Sciences, 80, 161-164. https://doi.org/10.1016/j.jseaes.2013.11.008

[15] Chen, C. H., Liu, J. Y., Lin, P. Y., Yen, H. Y., Hattori, K., Liang, W. T., \& Zeng, X. (2010). Pre-seismic geomagnetic anomaly and earthquake location. Tectonophysics, 489(1-4), 240-247. https://doi.org/10.1016/j.tecto.2010.04.018

[16] Han, P., Hattori, K., Xu, G., Ashida, R., Chen, C. H., Febriani, F., \& Yamaguchi, H. (2015). Further investigations of geomagnetic diurnal variations associated with the 2011 off the Pacific coast of Tohoku earthquake (Mw 9.0). Journal of Asian Earth Sciences, 114, 321-326. https://doi.org/10.1016/j.jseaes.2015.02.022

[17] Ding, J. H., Liu, J., Yu, S. R., \& Xiao, W. J. (2004). Geomagnetic diurnal-variation anomalies and their relation to strong earthquakes. Acta SeismologicaSinica, 17(1), 8593. https://doi.org/10.1007/s11589-004-0070-9

[18] Čop, R. (2017). Spremembagostote energije v zemeljskem magnetnem polju. Elektrotehniški vestnik, 84(4), 148-154.

[19] Pavlovčič-Prešeren, P., Čop, R., \& Kuhar, M. (2020). The Use of Geomagnetic Measurements to Study Local Tectonics: Case for the NE Part of the Adria-Eurasia Collisional Zone. Open Journal of Earthquake Research, 9 , 83-99. https://doi.org/10.4236/ojer.2020.92006

[20] Markušić, S., Stanko, D., Korbar, T., Belić, N., Penava, D., $\&$ Kordić, B. (2020). The Zagreb (Croatia) M5.5 Earthquake on 22 March 2020. Geosciences, 2020-10, 252. https://doi.org/10.3390/geosciences10070252

[21] https://www.intermagnet.org/index-eng.php/

[22] htttp://ftp.gfz-potsdam.de/pub/home/obs/kp-ap/

[23] https://www.pmf.unizg.hr/geof/znanost/ geomagnetizam $\mathrm{i}$ aeronomija

[24] http://www.intermagnet.org/data-donnee/downloadeng.php/
[25] Vujić, E., Brkić, M., \& Radović, N. (2011). Analysis of Croatian geomagnetic repeat station surveys in 2004 and 2007. StudiaGeophysica et Geodaetica, 55(4), 737-753. https://doi.org/10.1007/s11200-010-9037-6

[26] Brkić, M., Varga, M., Grgić, M., Radović, N., \& Bašić, T. (2020). Model radnog popravka kompasa za 2020. godinu. Strategos: Znanstveni časopis Hrvatskog vojnog učilišta" Dr.FranjoTuđman", 4(1), 7-29.

[27] Ivančić, I., Herak, D., Herak, M., Allegretti, I., Fiket, T., Kuk, K., \& Stipčević, J. (2018). Seismicity of Croatia in the period 2006-2015. Geofizika, 35(1), 69-98. https://doi.org/10.15233/gfz.2018.35.2

\section{Contact information:}

Mario BRKIĆ, Full professor

(Corresponding author)

Faculty of Geodesy, University of Zagreb,

Kačićeva 26, 10000 Zagreb, Croatia

E-mail: mario.brkic@geof.unizg.hr

Marijan GRGIĆ, Research Associate

Faculty of Geodesy, University of Zagreb,

Kačićeva 26, 10000 Zagreb, Croatia

E-mail: marijan.grgic@geof.unizg.hr

Nikol Radović, Senior Lecturer

Faculty of Geodesy, University of Zagreb,

Kačićeva 26, 10000 Zagreb, Croatia

E-mail: nikol.radovic@geof.unizg.hr 